\title{
Bronchial Muscle Peristaltic Activity in the Fetal Rat
}

\author{
OMAR PARVEZ, ANNE-MARIE VOSS, MASCHA DE KOK, MATTHIAS ROTH-KLEINER, AND JAQUES BELIK \\ Department of Pediatrics, Hospital for Sick Children, Toronto, Ontario, Canada, M5G 1X8
}

\begin{abstract}
Aside for the potential for tonic contraction, the airway smooth muscle exhibits intermittent phasic rhythmic activity that may contribute to lung growth during fetal life. Therefore, we examined 4th generation rat $18-22 \mathrm{~d}$ gestation fetal, 4-6 d of age newborn and adult bronchial ring from Sprague Dawley rats to compare differences in smooth muscle function. We hypothesized that phasic contractions were greatest before birth. Bronchial muscle spontaneous rhythmic contractions were greatest in the fetus and absent in the adult. In response to $\mathrm{KCl}$ stimulation, the fetal bronchial smooth muscle only developed tonic force that was $3.5 \pm 0.6$ and lower than measured in the newborn $9.0 \pm 0.3$ and adult $13.7 \pm$ $1.4 \mathrm{mN} / \mathrm{mm}^{2}$. The thromboxane $\mathrm{A}_{2}$ analogue $\mathrm{U} 46619$ induced tonic and phasic muscle contractions and the amplitude and frequency of the phasic contractions were greater in the fetus as compared with the adult and increased with gestational age. The U46619-induced rhythmic contractions were abrogated by ryanodine, thapsigargin and reduction of extracellular $\mathrm{Na}^{+}$, suggesting intracellular $\mathrm{Ca}^{2+}$ dependence and involvement of the $\mathrm{Na}^{+} / \mathrm{Ca}^{2+}$ exchanger. The inward rectifier $\mathrm{K}^{+}$blocker $\mathrm{BaCl}_{2}$ induced phasic contractions in unstimulated fetal, but not adult bronchial muscle of the same amplitude and frequency as for the spontaneous and U46619-induced ones. We conclude that the airway smooth muscle phasic activity is greatest in the fetus and tends to disappear post-natally with age suggesting an in utero role during lung development. (Pediatr Res 59: 756-761, 2006)
\end{abstract}

A lthough airway smooth muscle contraction is an integral part of the acute and chronic bronchoconstriction observed in conditions such as asthma, the role of this musculature in health is unclear (1). As opposed to the tonic muscle activity that determines the airway caliber and is responsible for bronchoconstriction, phasic spontaneous activity has been described in the trachea and smaller airway muscle of adult rabbits $(2)$, humans $(3,4)$ and guinea pigs $(5)$. This phasic activity, however, is intermittent and not present in all airway smooth muscle in vitro preparations.

Recently, the existence of spontaneous bronchial muscle phasic activity in fetuses has been recognized (6,7). Its physiologic significance remains obscure, but McCray et al. (7), Schittny et al. (8), and more recently, Jesudason (9) suggested that such airway phasic contractions play an important role in the maintenance of adequate alveolar distention. Yet others have raised objections to this speculation (10).

We reasoned that if the airway muscle phasic contractions are of importance to fetal lung growth this activity would be greatest before and progressively disappear after birth. Therefore the purpose of the present study was to compare phasic activity of airway muscle in fetal, neonatal and adult rats, as well as study the mechanism responsible for this oscillatory behavior.

Given that in fetal lung explants bronchial peristalsis was observed in small airways we studied near resistance fourth generation bronchi. In addition to recording their spontaneous activity the bronchial muscle was stimulated with voltagedependent agonist $\mathrm{KCl}$ and the thromboxane $\mathrm{A}_{2}$ analogue U46619. The latter agonist has been shown to induce both tonic and phasic contractions in certain smooth muscle containing tissues (11).

\section{METHODS}

Sprague-Dawley rats (Charles River, Saint-Constant, Quebec, Canada) were used for these studies. We evaluated 12 adults, 52 fetuses and 39 newborn animals. The fetuses were delivered at $18(n=11), 21(n=3)$ or $22 \mathrm{~d}(n=38)$ gestation (term $=22 \mathrm{~d})$ by cesarean section following pentobarbital sodium anesthesia ( $25 \mathrm{mg} / \mathrm{kg}$ IP). The newborn (4-6 d) and adult ( $2 \mathrm{mo}$ ) animals were killed with an overdose of pentobarbital sodium (50 $\mathrm{mg} / \mathrm{kg}$ IP). All animals had their lungs removed immediately after death.

This research protocol was approved by the Hospital for Sick Children Animal Care Committee.

Organ bath studies. Fourth generation left lung intralobar bronchial rings (average diameter 70-100 $\mu \mathrm{m}$ and length $=2 \mathrm{~mm}$ ) were dissected free and mounted on a wire myograph (Danish Myo Technology A/S, Denmark). Isometric changes were digitized and recorded online (Myodaq, Danish Myo Technology A/S, Denmark). Tissues were bathed in Krebs-Henseleit buffer $\left(\mathrm{NaCl}, 115 \mathrm{mM} ; \mathrm{NaHCO}_{3}, 25 \mathrm{mM} ; \mathrm{NaHPO}_{4}, 1.38 \mathrm{mM} ; \mathrm{KCl}, 2.51 \mathrm{mM}\right.$; $\mathrm{MgSO}_{4} \cdot 7 \mathrm{H}_{2} \mathrm{O}, 2.46 \mathrm{mM} ; \mathrm{CaCl}_{2}, 1.91 \mathrm{mM}$; and dextrose, $5.56 \mathrm{mM}$ ), bubbled with air $/ 6 \% \mathrm{CO}_{2}$ and maintained at $37^{\circ} \mathrm{C}$.

After $1 \mathrm{~h}$ of equilibration, the optimal resting tension of the tissue was determined by repeated stimulation with $128 \mathrm{mM} \mathrm{KCl}$ until maximum active tension was reached. All subsequent force measurements were obtained at optimal resting tension. Contractile responses were normalized to the tissue cross-sectional area as follows: (width $\times$ diameter) $\times 2$ and expressed as $\mathrm{mN} / \mathrm{mm}^{2}$, as previously described (12).

Determination of bronchial contractility. $\mathrm{KCl}(128 \mathrm{mM}$ prepared by equimolar substitution for $\mathrm{NaCl}$ in the Krebs-Henseleit solution) and the thromboxane $\mathrm{A}_{2}$ analogue $\mathrm{U} 46619$ were used to evaluate the airway muscle 
tonic contraction. The bronchial muscle phasic activity was evaluated under optimal resting tension (spontaneous) and following stimulation with the thromboxane $\mathrm{A}_{2}$ analogue $\mathrm{U} 46619$ at tonic $\mathrm{EC}_{50}$ concentration (determined in preliminary studies to be $10^{-7} \mathrm{M}$ ).

To address the mechanism responsible for the bronchial phasic contractility, studies were also performed utilizing the non-specific cyclooxygenase blocker indomethacin (Sigma Chemical Co., Oakville, Ontario, Canada), the RYR inhibitor ryanodine (Calbiochem, San Diego, CA, USA), the sarcoendoplasmic reticulum $\mathrm{Ca}^{2+}$-ATPase (SERCA) pump inhibitor thapsigargin (Research Biochemicals International, Natick, MA, USA), the potassium channel blockers barium chloride, glibenclamide and 4-aminopiridine (Sigma Chemical Co., Oakville, Ontario, Canada) and the Rho-kinase inhibitor Y27632 (Calbiochem, San Diego, CA). All drugs were mixed in water and the bronchial contractility assessed for a period of $5 \mathrm{~min}$ before and after the addition of the drugs. A reduced- $\mathrm{Na}^{+}$Krebs solution was prepared by equimolar replacement of $\mathrm{NaCl}$ with choline chloride (Sigma Chemical Co., Oakville, Ontario, Canada).

Statistical analysis. Statistical comparisons were done by either one- or two-way analysis of variance (ANOVA) or the $t$-test as indicated utilizing the Number Cruncher Statistical Package software (NCSS Kaysville, UT) Data are reported as Mean $\pm \mathrm{SE}$ and a $p<0.05$ was considered statistically significant.

\section{RESULTS}

Maturational differences in bronchial muscle tonic contraction. In response to $\mathrm{KCl}$ stimulation, the adult bronchial smooth muscle tonic active maximal force was $13.7 \pm 1.4$ and significantly higher $(p<0.01)$ than measured in the newborn $9.0 \pm 0.3$ and fetus $3.5 \pm 0.6 \mathrm{mN} / \mathrm{mm}^{2}$ (Fig. 1). A similar pattern of maturational differences in force development was observed in response to U46619 stimulation.

Maturational differences in bronchial muscle phasic contractions. Representative tracings of the fetal, newborn and adult bronchial muscle spontaneous phasic contractions are shown in Fig. 2. The magnitude and pattern of phasic contractions were age-dependent, but in contrast with the tonic force of greater amplitude and frequency in the fetal and newborn airways, as compared with the adult.

Given that the spontaneous phasic activity of the fetus and newborn was not regular and continuous, we sought to consistently reproduce it via stimulation with the thromboxane $\mathrm{A}_{2}$ analogue U46619, as used by others (13). U46619 $\mathrm{EC}_{50}$ $\left(10^{-7} \mathrm{M}\right)$ induced phasic activity was only present in the fetal and newborn bronchial muscle in a pattern similar to the one

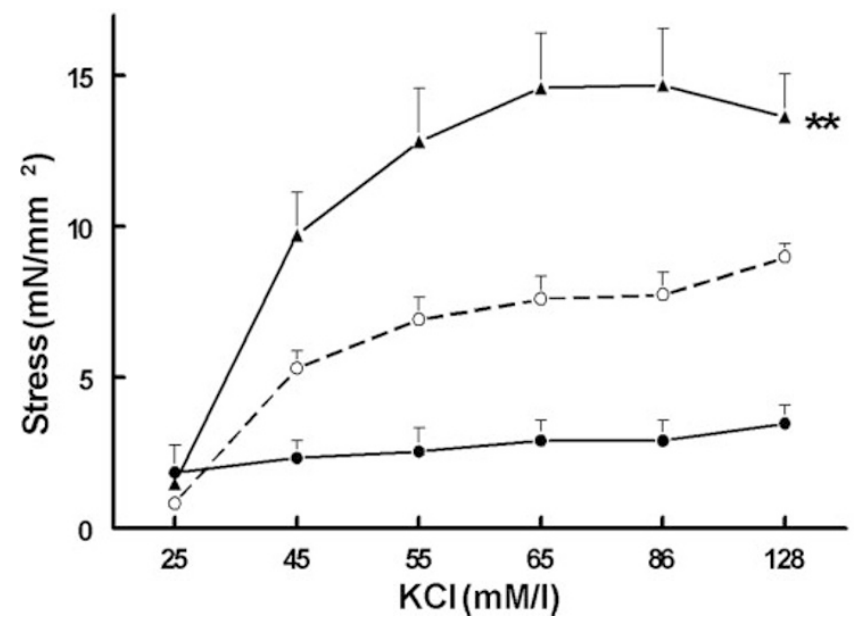

Figure 1. Twenty-two days gestation fetal (,$n=3)$, newborn (TM, $n=6$ ) and adult $(\pi, n=12)$ bronchial muscle response to $\mathrm{KCl}$ stimulation. $* * p<$ 0.01 versus fetal and newborn values by two-way analysis of variance.

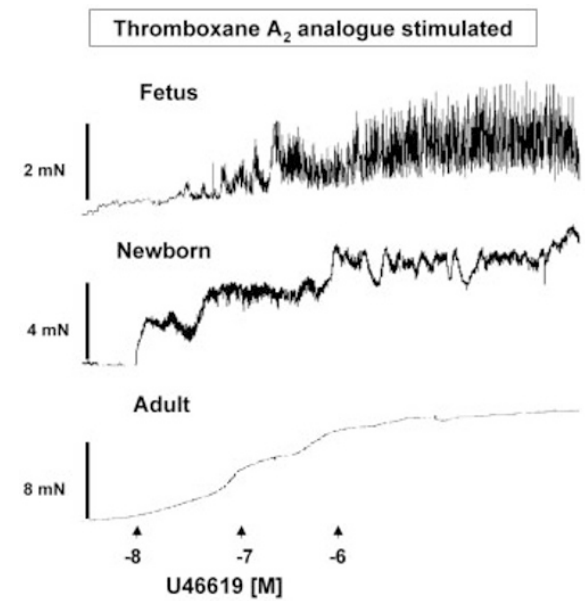

Spontaneous
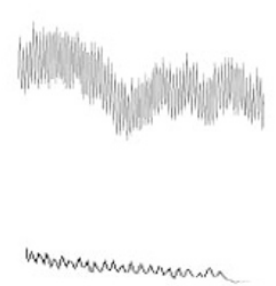

Figure 2. Representative tracings of thromboxane $A_{2}$ analogue U46619induced tonic and phasic contractions and unstimulated spontaneous phasic activity of fetal, newborn and adult bronchial smooth muscle. Note that the rhythmic phasic activity is almost absent in the adult and of greatest magnitude in the fetus in the spontaneous and U46619-induced contractions

observed for the spontaneous contractions (Fig. 2). No phasic contractions were seen at any age in response to $\mathrm{KCl}$ stimulation.

Figure 3 illustrates the amplitude and frequency of the bronchial muscle phasic contractions as a percentage of U46619-induced force. The phasic contractions amplitude was significantly higher in the fetus, as compared with the newborn and adult, whereas the frequency was similar in fetal and newborn tissue but significantly different from adults. As illustrated in Fig. 4, the phasic activity expressed as amplitude $\times$ frequency of the fetal bronchial muscle significantly increased $(p<0.01)$ as gestation progressed and was highest at term.

Role of prostaglandins and rho-kinase. To further evaluate the mechanism responsible for the bronchial muscle phasic activity, all studies were done utilizing fetal bronchi stimulated with U46619 $\mathrm{EC}_{50}\left(10^{-7} \mathrm{M}\right)$.

Given the developmental changes in lung prostaglandin levels and their unique role in fetal life such as the maintenance of ductus arteriosus patency we investigated the effect of a cyclooxygenase inhibitor upon the bronchial phasic activity. Indomethacin $\left(10^{-5} \mathrm{M}\right)$ had no effect on the amplitude and frequency of the U46619-induced fetal phasic contractions, suggesting no involvement of cyclooxygenase products in this process.
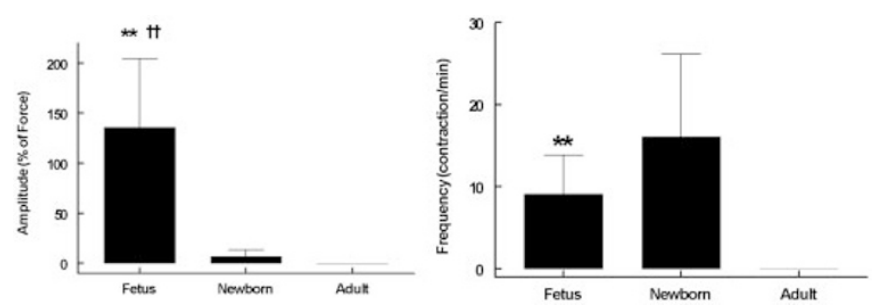

Figure 3. Amplitude (expressed as percentage of the active force) and frequency of the U46619-induced $\left(10^{-7} \mathrm{M}\right)$ bronchial muscle phasic contraction in 22 days gestation fetal $(n=20)$, newborn $(n=12)$ and adult $(n=5)$ tissue. $* * p<0.01$ vs adult; $\dagger \dagger p<0.01$ versus newborn by one-way ANOVA and Tukey-Krammer multiple comparison test. 


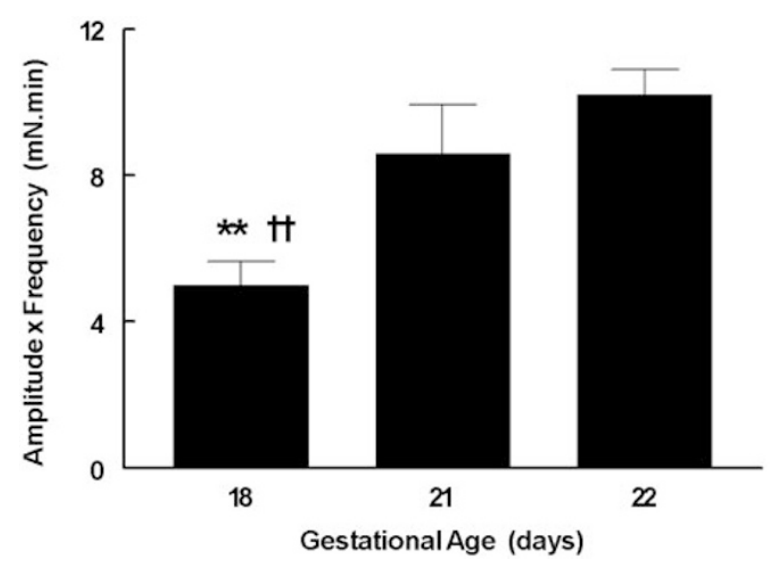

Figure 4. Bronchial muscle peristaltic activity represented as the product of amplitude $\times$ frequency of U46619-induced $\left(10^{-7} \mathrm{M}\right)$ from $18(n=11), 21$ $(n=3)$ and $22 \mathrm{~d}$ gestation $(n=3)$ fetal rats. $* * p<0.01$ versus $22 \mathrm{~d}$; $\dagger \dagger p$ $<0.01$ versus $21 \mathrm{~d}$ by one-way ANOVA and Tukey-Krammer multiple comparison test.

We further investigated whether Rho-kinase had played a role inducing phasic activity via increased $\mathrm{Ca}^{2+}$ sensitization. The rationale for this set of experiments related to our recently published data showing that pulmonary arterial smooth muscle Rho-kinase activity is highest in the fetus (14) and the observation by others that this enzyme is involved in embryonic organogenesis (15). Therefore we investigated the effect of Y27632, a Rho-kinase inhibitor, on the U44619-induced fetal bronchial phasic contractions. Progressively increased Y27632 molar concentration $\left(10^{-9}\right.$ to $\left.10^{-6} \mathrm{M}\right)$ resulted in a significant decrease of the U46619-induced tonic contraction from $2.7 \pm 0.1 \mathrm{mN}$ to $1.9 \pm 0.1 \mathrm{mN}$ at $10^{-6} \mathrm{M}$ of $\mathrm{Y} 27632$ $(p<0.01)$. Yet the U46619-induced phasic contraction amplitude was $0.9 \pm 0.1$ before and $0.7 \pm 0.1 \mathrm{mN}$ in the presence of Y27632 $10^{-6} \mathrm{M}$ concentration $(n=4 ; p=\mathrm{NS})$ suggesting that rho-kinase activity is not responsible for the phasic activity of the fetal bronchial muscle.

Role of extra and intracellular $\mathrm{Ca}^{2+}$ pools. Calcium free media and the $\mathrm{Ca}^{2+}$ chelator EGTA resulted in complete suppression of the U46619-induced tonic, as well as phasic bronchial muscle contractions indicating that both are dependent on the extracellular calcium concentration.

To investigate the role of intracellular calcium pools we used the RyR channel inhibitor ryanodine and the SERCA pump inhibitor thapsigargin. Ryanodine $(10 \mu \mathrm{M})$ selectively diminished the U46619-stimulated fetal bronchi rhythmic activity frequency with no effect on the tonic component of the contractions (Fig. 5). Thapsigargin $\left(10^{-6} \mathrm{M}\right)$ significantly ( $p$ $<0.01$ ) reduced the frequency, but not amplitude of the phasic contractions (Fig. 6) Together these data suggest involvement of the RyR and thapsigargin-sensitive $\mathrm{Ca}^{2+}$ stores in the mechanism of phasic contractions.

Contribution of potassium channel activity to the phasic contractions. Membrane ion channels play an important role in smooth muscle excitability and $\mathrm{K}^{+}$channels are known to play an important role in the resting potential of airway smooth muscle (16). For this reason we tested the effect of $\mathrm{K}^{+}$ channel blockade on the fetal bronchial muscle U46619induced phasic contractions. The $\mathrm{K}_{\mathrm{ATP}}$ inhibitor gliben-

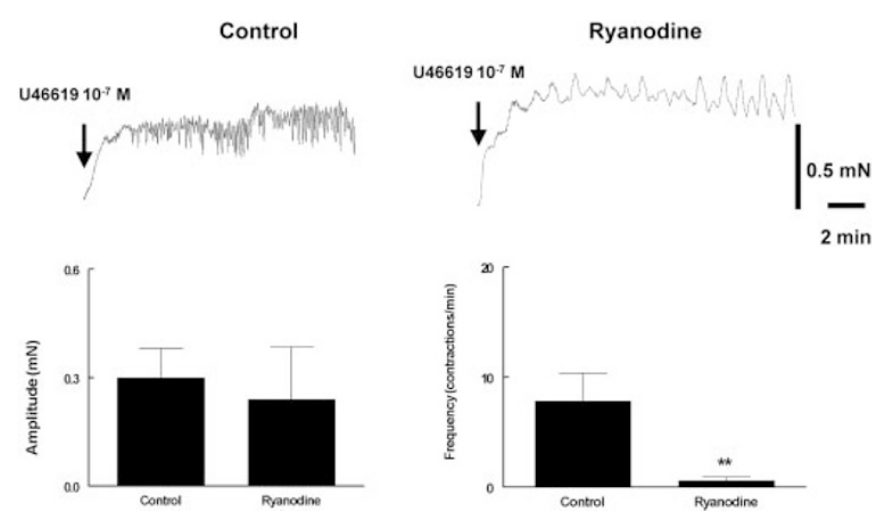

Figure 5. Amplitude and frequency of the U46619-induced $\left(10^{-7} \mathrm{M}\right)$ bronchial muscle phasic response in fetal bronchial muscle $(n=3)$ in the absence (control) and presence of ryanodine $(10 \mu \mathrm{M})$. $* * p<0.01$ versus control by paired $t$-test.

Control

Thapsigargin

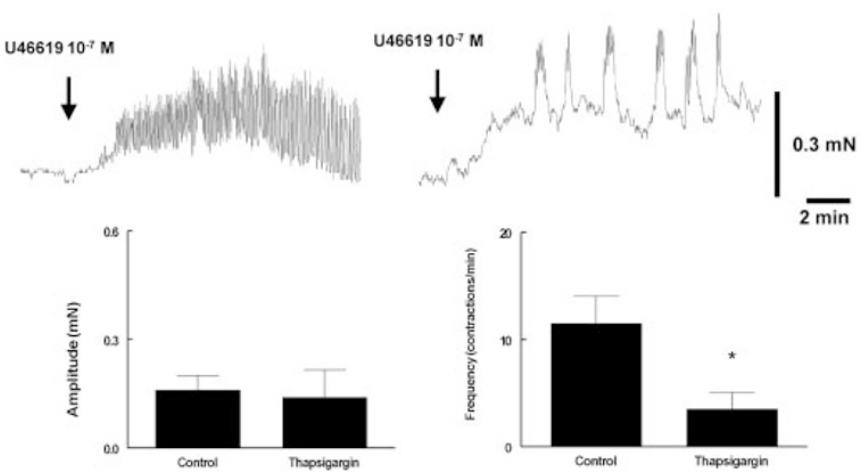

Figure 6. Amplitude and frequency of the U46619-induced $\left(10^{-7} \mathrm{M}\right)$ bronchial muscle phasic response in fetal bronchial muscle $(n=4)$ in the absence (control) and presence of thapsigargin $\left(10^{-6} \mathrm{M}\right) . * p<0.05$ versus control by paired $t$-test.

clamide $\left(10^{-5} \mathrm{M}\right)$ had no effect on the amplitude $(1.2 \pm 0.2$ versus $1.4 \pm 0.14 \mathrm{mN})$ or frequency $(6.5 \pm 0.85$ versus $7.8 \pm$ 0.6 contractions $/ \mathrm{min}$ ) as compared with the control U46619induced bronchial muscle phasic contractions $(n=4)$. Similar lack of effect was observed with the $\mathrm{K}_{\mathrm{v}}$ channel blocker 4 aminopyridine $\left(10^{-5} \mathrm{M}\right)$ where the amplitude was $0.26 \pm$ 0.05 versus $0.16 \pm 0.04$ and the frequency $7.7 \pm 1.8$ versus $7.8 \pm 1$ as compared with control values $(n=4)$.

Addition of the inward rectifier $\mathrm{K}^{+}$current inhibitor $\mathrm{BaCl}_{2}$ $\left(10^{-3} \mathrm{M}\right)$ had no effect on the amplitude and frequency of U46619-induced bronchial muscle phasic contraction in the fetus. Yet, when fetal bronchial rings were exposed to $\mathrm{BaCl}_{2}$ $\left(10^{-3} \mathrm{M}\right)$ without U46619 stimulation, an immediate and persistent phasic muscle activity was observed (Fig. 7). The amplitude and frequency of the $\mathrm{BaCl}_{2}$-induced contractions were comparable with the spontaneous and U466i9-induced rhythmic activity. Exposure of adult bronchial muscle to $\mathrm{BaCl}_{2}\left(10^{-3} \mathrm{M}\right)$ did not induce phasic or tonic contractions.

$\mathrm{Na}^{+} / \mathrm{Ca}^{2+}$ and $\mathrm{Na}^{+} / \mathrm{H}^{+}$exchange and phasic contractions. The potential role of $\mathrm{Na}^{+} / \mathrm{Ca}^{2+}$ exchanger in the fetal bronchial muscle U46619-induced phasic contractions was investigated because thoracic duct smooth muscle peristaltic activity is dependent on this channel (11). The fetal bronchial muscle U46619-induced phasic contractions amplitude was 

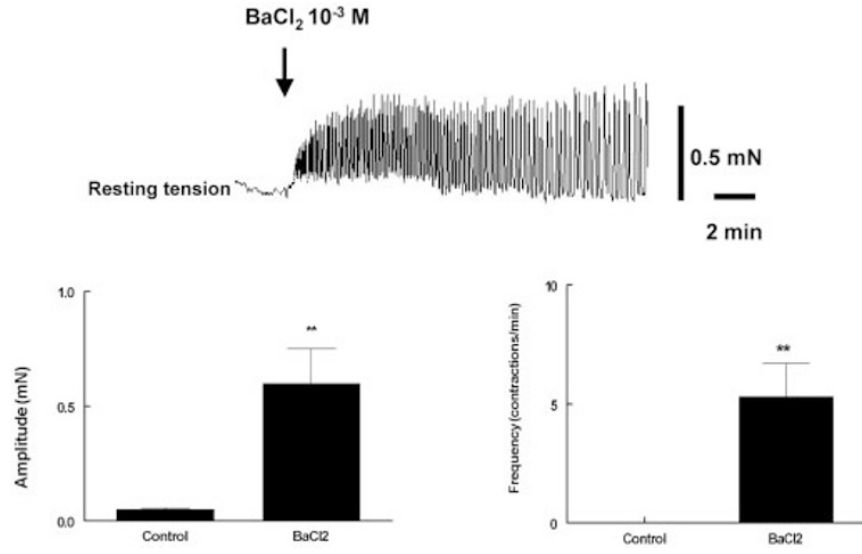

Figure 7. Amplitude and frequency of the fetal bronchial spontaneous muscle phasic response $(n=4)$ in the absence (control) and presence of barium chloride $\left(10^{-3} \mathrm{M}\right)$. ** $p<0.01$ versus control by paired $t$-test.

significantly $(p<0.01)$ abrogated in sodium-reduced buffer (Fig. 8) suggesting involvement of the $\mathrm{Na}^{+} / \mathrm{Ca}^{2+}$ exchanger. To exclude the possibility of such a suppressive response being related to the $\mathrm{Na}^{+} / \mathrm{H}^{+}$channel activity, we evaluated the effect of and inhibitor of this channel (amiloride) on the U46619-induced peristaltic motion. The amplitude of fetal bronchial muscle $(n=4)$ phasic activity following amiloride $\left(10^{-4} \mathrm{M}\right)$ treatment was $0.6 \pm 0.2$ and not significantly different from control $0.4 \pm 0.05 \mathrm{mN}$ ). Similarly, amiloride had no effect on the U46619-induced frequency of phasic contraction in the fetal bronchial muscle (amiloride $=5.8 \pm$ 1.85 versus control $=8.5 \pm 2.6$ contractions $/ \mathrm{min}$ ).

\section{DISCUSSION}

Aside from its mainly tonic force generation the airway muscle also exhibits a phasic like activity (4). In 1924, Lewis (17) was the first to report spontaneous airway contractility in chick embryos with a frequency of 2 contractions/min. Airway muscle phasic activity has been subsequently reported by others to be present in the postmortem tissue from adult $(4,18,19)$ and fetal humans $(7)$, as well as in some animal species $(2,20,21)$. Such phasic activity is not unique to the
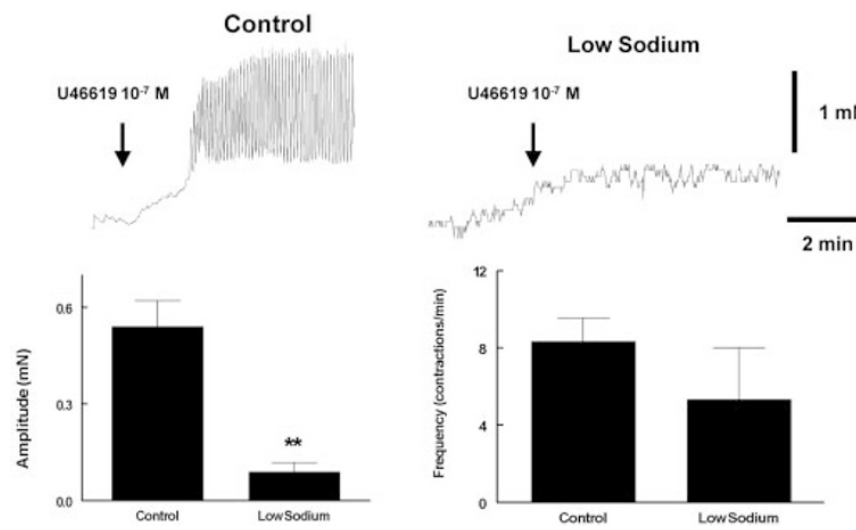

Figure 8. Amplitude and frequency of the U46619-induced $\left(10^{-7} \mathrm{M}\right)$ bronchial muscle phasic response in fetal bronchial muscle $(n=3)$ in KrebsHenseleit (control) and sodium free buffer. $* * p<0.01$ versus control by paired $t$-test. airway and is also present in lymphatic vessels (22), the thoracic duct (11), systemic arteries (13) and bladder smooth muscle (23).

In the adult human and animal tissue the airway muscle phasic activity is intermittent and not always present (2-4). In the present study we observed the highest spontaneous and U46619-induced bronchial muscle activity in the fetal rat at term with an average frequency of 10 contractions $/ \mathrm{min}$. The U46619-stimulated rhythmic contractions increased with gestational age in utero and were of maximal activity at term. Following birth, these phasic contractions decreased and were absent in the adult rat bronchi. The pattern observed for the phasic contractions contrasts with the age-dependent increase in tonic force development of the bronchial muscle in the rat.

Although the present study involved bronchial ring segments studied in vitro, the fetal airway muscle rhythmic activity under these conditions was similar to the one reported by Schittny in freshly isolated pig and rabbit, as well as cultured mouse fetal lungs (8). The use of the thromboxane $\mathrm{A}_{2}$ agonist U46619 to stimulate phasic contractions in this study was necessary to induce consistent and reproducible phasic activity to allow further evaluation of its mechanism. Aside from its powerful smooth muscle tonic contraction response, U46619 has been shown by others to induce phasic activity in the thoracic duct (11), coronary arteries (24), and dog lingual and mesenteric arteries (25). Of interest is the fact that following $\mathrm{KCl}$ stimulation the fetal bronchial muscle develops tonic force without phasic contractions suggesting that the mechanism by which U46619 induces rhythmic activity does not depend on the tonic force.

The mechanism responsible for the airway muscle phasic activity in the fetus is presently unclear, but available data indicate the following. It is independent of the airway innervation since atropine and tetrodotoxin do not suppress such phasic activity (7). Calcium channel blockade with nifedipine halted airway rhythmic contractility in the murine explant (26) and human lung (7). In the embryonic rat lung peristaltic airway activity was dependent on extracellular calcium entry via L-type voltage-gated and intracellular $\mathrm{Ca}^{2+}$ stores (27).

In the present study we sought to further evaluate the mechanism involved in the spontaneous contractions by studying the U46619-induced phasic contractions. That this thromboxane $\mathrm{A}_{2}$ analogue-induced phasic contractions mimic the spontaneous ones is best illustrated by the similarities between the present study utilizing U46619 and Featherstone et al. data on the spontaneous peristaltic waves of the fetal rat airway (27). In both preparations the phasic activity was suppressed by removal of extracellular calcium and blockade of SERCA and RyR regulated internal calcium stores.

We have demonstrated in the present study that the bronchial muscle rhythmic contractions were also abrogated by a reduction of extracellular $\mathrm{Na}^{+}$and amiloride at concentrations known to inhibit $\mathrm{Na}^{+} / \mathrm{H}^{+}$exchange did not affect the phasic contractions. Together these findings suggest that the fetal bronchial muscle phasic activity depend on the $\mathrm{Na}^{+} / \mathrm{Ca}^{2+}$ exchanger. Similar findings of $\mathrm{Na}^{+} / \mathrm{Ca}^{2+}$ involvement in U46619-stimulated rhythmic smooth muscle contractions have been reported for the pig thoracic duct (11). Coupling of 
the $\mathrm{Na}^{+} / \mathrm{Ca}^{2+}$ exchanger with $\mathrm{Ca}^{2+}$ release from intracellular stores has been shown in the guinea pig ileal smooth muscle (28) and a similar mechanism may be involved in the fetal rat airway phasic activity.

We further evaluated the potential role of potassium currents in the phasic activity of the fetal bronchial muscle.. The four classes of $\mathrm{K}^{+}$channels known to exist in the airway smooth muscle include the $\mathrm{Ca}^{2+}$-dependent $\left(\mathrm{K}_{\mathrm{Ca}}\right)$, voltagedependent $\left(\mathrm{K}_{\mathrm{v}}\right)$, ATP-dependent $\left(\mathrm{K}_{\mathrm{ATP}}\right)$ and inward rectifier $\left(K_{I R}\right)$ (29). Inhibition of $K_{C a}$ channels in the fetal rat lung did not significantly alter the amplitude of peristaltic activity (27). In this study we found a similar lack of effect on fetal bronchial muscle U46619-induced phasic contractions amplitude and frequency when exposed to the $\mathrm{K}_{\mathrm{v}}$ inhibitor 4-aminopyridine and the $\mathrm{K}_{\mathrm{ATP}}$ blocker glibenclamide. Yet the $\mathrm{K}_{\mathrm{IR}}$ inhibitor $\mathrm{BaCl}_{2}$ induced spontaneous contractions in the fetal, but not adult bronchial muscle. The $\mathrm{BaCl}_{2}$-induced peristaltic activity was of similar amplitude and frequency that of the U46619 stimulated.

$\mathrm{K}_{\mathrm{IR}}$ current was once believed to be non existent in airway smooth muscle (29), yet recently Snetkov et al. documented its existence in human small (but not large) airway smooth muscle (16). In addition, Snetkov et al. studying fetal human airway smooth muscle cells documented a strong similarity between these and their adult equivalent (30). In freshly isolated fetal cells a non-contractile proliferative phenotype is observed in $50 \%$, as opposed to the adult human airway smooth muscle where almost all cells are contractile. When adult human bronchial smooth muscle cells are placed in culture and become proliferative a significant number of them exhibit inward rectifying $\mathrm{K}^{+}$current (31). Taken together these data suggest that $\mathrm{K}_{\mathrm{IR}}$ channels are only existent in bronchial smooth muscle cells during fetal life and may have an important role in the mechanism accounting for airway peristaltic activity prenatally.

The possible role of Rho-kinase-induced $\mathrm{Ca}^{2+}$ sensitization on the mechanism accounting for bronchial muscle phasic activity was also investigated. It is widely known that muscle contraction is not only the result of an increase in intracellular $\mathrm{Ca}^{2+}$ concentration, but also $\mathrm{Ca}^{2+}$ sensitization (32). U46619 induces smooth muscle contraction in certain tissues by $\mathrm{Ca}^{2+}$ sensitization in a manner that is reversible by the Rho-kinase specific inhibitor Y27632 (33-35). To evaluate the Rho-kinase pathway involvement in the U46619-induced fetal bronchial peristatic activity we progressively increased the Y27632 concentration of pre-stimulated bronchial muscle until a significant reduction in tonic force was observed. No change in the amplitude of phasic contraction was noted in the fetal bronchial muscle suggesting that this activity is not $\mathrm{Ca}^{2+}$ sensitization mediated.

A cartoon illustrating the site of action of all tested compounds with an effect on the tonic and phasic contraction are shown in Fig. 9. Based on the evidence of the present study and previously published observations, we speculate that the mechanism responsible for the bronchial muscle peristaltic activity is as follows. Cyclical inactivation of bronchial smooth muscle membrane $\mathrm{K}_{\mathrm{IR}}$ (mostly present in the fetus) causes membrane potential depolarization via activation of

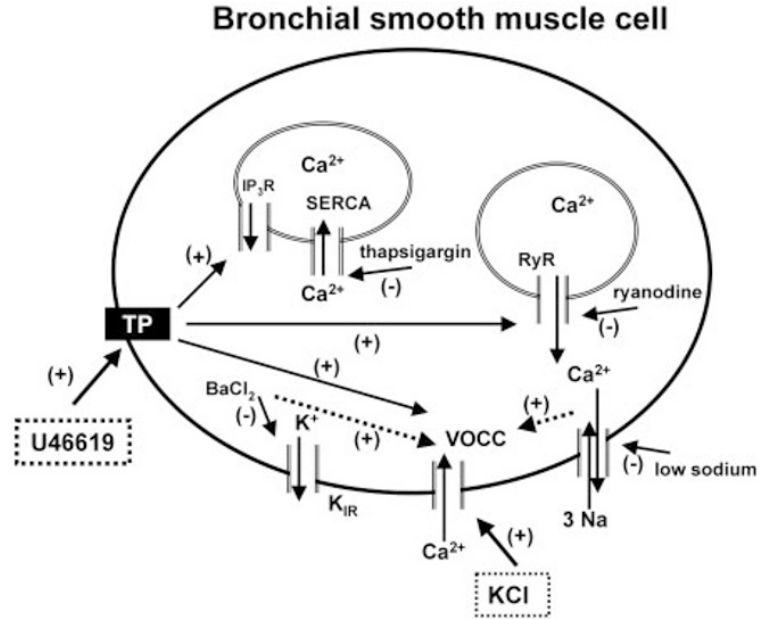

Figure 9. Illustrative cartoon of the site of action of the agonists and antagonist used to evaluate the mechanism responsible for the fetal bronchial phasic contractions. RyR, ryanodine receptor; U46619, thromboxane $\mathrm{A}_{2}$ analogue; SERCA, sarcoendoplasmic reticulum $\mathrm{Ca}^{2+}$-ATPase; $\mathrm{IP}_{3} \mathrm{R}$, inositol triphosphate receptor; VOCC, voltage operated calcium channel; TP, thromboxane receptor

L-type VOCC $\mathrm{Ca}^{2+}$ channels. This result in an influx of extracellular $\mathrm{Ca}^{2+}$ and activation of SERCA and RyR pumps leading to depletion and refilling of intracellular $\mathrm{Ca}^{2+}$ stores. This together with $\mathrm{Ca}^{2+}$ extrusion from the intracellular compartment via the $\mathrm{Na}^{+} / \mathrm{Ca}^{2+}$ exchanger result in the oscillatory phasic behavior of the fetal bronchial muscle.

Lung growth is dependent on expansion of peripheral airspaces and related to the fluid pressure in the lungs during gestation (36). This pressure is presumed to be caused by secretion of liquid into the lung lumen and the occlusion of the airways at the level of the glottis. Aside from the presence of adequate amounts of lung fluid, fetal breathing leads to further distention of the alveoli. This rhythmic activity is thought to have an important role in lung growth, since fetal breathing suppression by phrenic nerve section leads to lung hypoplasia $(37,38)$. Aside from breathing the fetal airway smooth muscle peristaltic activity may also play an important role toward lung growth. In fact, the only suggested physiologic function of airway muscle relates to its potential role during fetal life on the promotion of lung growth $(8,9)$ leading to the speculation that post-natally the bronchial muscle is merely an appendix of the lung (1).

Whether the regulation of fetal breathing and bronchial contractility follows a similar pathway is unknown. Fetal breathing in humans increases with gestational age and is greatest near term (39). Schittny et al. reported consistent airway muscle phasic activity as early as 11 to $12 \mathrm{~d}$ in the fetal mice, 25 to $56 \mathrm{~d}$ in the fetal pigs and $27 \mathrm{~d}$ gestation in rabbits with the frequency of contractions late in gestation ranging from 2 to $12 /$ minute (8). In the rat, periods of continuous fetal breathing are only detected on day $18^{\text {th }}$ of gestation and progressively increase in duration until term (40). In the present study we demonstrated that the rhythmic activity of fetal bronchial muscle progressively increases after $18 \mathrm{~d}$ and is maximal at $22 \mathrm{~d}$ gestation in the rat, averaging 8/minute. Together these data suggest that the fetal breathing and bron- 
chial rhythmic phasic activity follow the same in utero maturational pattern, possibly because of their complementary role in the promotion of lung growth.

In summary, spontaneously observed, $\mathrm{BaCl}_{2}$-mediated and thromboxane $\mathrm{A}_{2}$ analogue-induced rhythmic contractions are of greatest amplitude in the fetal airways and likely related to the unique characteristics of the fetal airway smooth muscle cells. The predominance of bronchial rhythmic phasic activity during fetal life supports the speculation that the airway muscle plays an important role toward lung growth before birth.

Acknowledgments. This work was supported by an operating grant from the Canadian Institutes for Health and Research

\section{REFERENCES}

1. Mitzner W 2004 Airway smooth muscle: the appendix of the lung. Am J Respir Crit Care Med 169:787-790

2. Fujiwara T, Itoh T, Kuriyama H 1988 Regional differences in the mechanical properties of rabbit airway smooth muscle. Br J Pharmacol 94:389-396

3. Ito Y, Suzuki H, Aizawa H, Hakoda H, Hirose T 1989 The spontaneous electrical and mechanical activity of human bronchial smooth muscle: its modulation by drugs. Br J Pharmacol 98:1249-1260

4. Davis C, Kannan MS, Jones TR, Daniel EE 1982 Control of human airway smooth muscle: in vitro studies. J Appl Physiol 53:1080-1087

5. Tagliente TM, Dalton BA, Be Harari RR 1992 Phasic responses to carbachol in isolated guinea pig trachea are augmented by cooling and inhibited by nifedipine. J Pharmacol Exp Ther 261:755-763

6. Richards IS, Kulkarni A, Brooks SM 1991 Human fetal tracheal smooth muscle produces spontaneous electromechanical oscillations that are $\mathrm{Ca} 2+$ dependent and cholinergically potentiated. Dev Pharmacol Ther 16:22-28

7. McCray PBJr 1993 Spontaneous contractility of human fetal airway smooth muscle. Am J Respir Cell Mol Biol 8:573-580.

8. Schittny JC, Miserocchi G, Sparrow MP 2000 Spontaneous peristaltic airway contractions propel lung liquid through the bronchial tree of intact and fetal lung explants. Am J Respir Cell Mol Biol 23:11-18

9. Jesudason EC, Smith NP, Connell MG, Spiller DG, White MR, Fernig DG, Losty PD 2005 Developing rat lung has a sided pacemaker region for morphogenesisrelated airway peristalsis. Am J Respir Cell Mol Biol 32:118-127

10. Nakamura KT, McCray PBJr 2000 Fetal airway smooth-muscle contractility and lung development. A player in the band or just someone in the audience? Am J Respir Cell Mol Biol 23:3-6

11. Moffatt JD, Cocks TM 2004 Pharmacologically distinct intracellular calcium pools regulate tonic and oscillatory responses in porcine thoracic duct. J Cardiovasc Pharmacol 43:83-92

12. Belik J, Jankov RP, Pan J, Tanswell AK 2003 Chronic O2 exposure enhances vascular and airway smooth muscle contraction in the newborn but not adult rat. J Appl Physiol 94:2303-2312

13. Shaw L, O'Neill S, Jones CJ, Austin C, Taggart MJ 2004 Comparison of U46619-, endothelin-1- or phenylephrine-induced changes in cellular $\mathrm{Ca} 2+$ profiles and $\mathrm{Ca} 2+$ sensitisation of constriction of pressurised rat resistance arteries. $\mathrm{Br} \mathrm{J}$ Pharmacol 141:678-688

14. Belik J, Kerc E, Pato MD 2006 Rat pulmonary arterial smooth muscle myosin light chain kinase and phosphatase activities decrease with age. Am J Physiol Lung Cell Mol Physiol 290:L509-L516

15. Wei L, Roberts W, Wang L, Yamada M, Zhang S, Zhao Z, Rivkees SA, Schwartz RJ, Imanaka-Yoshida K 2001 Rho kinases play an obligatory role in vertebrate embryonic organogenesis. Development 128:2953-2962
16. Snetkov VA, Ward JP 1999 Ion currents in smooth muscle cells from human small bronchioles: presence of an inward rectifier $\mathrm{K}+$ current and three types of large conductance K+ channel. Exp Physiol 84:835-846

17. Lewis M 1924 Spontaneous rhythmical contraction of the muscles of the bronchial tubes and air sacs of the chick embryo. Am J Physiol 68:385-388

18. Chideckel EW, Frost JL, Mike P, Fedan JS 1987 The effect of ouabain on tension in isolated respiratory tract smooth muscle of humans and other species. Br J Pharmacol 92:609-614

19. Sollmann T, Gilbert AJ 1937 Microscopic observations on bronchiolar reactions. J Pharmacol Exp Ther 61:272-285

20. Sato T, Hirota K, Matsuki A, Zsigmond EK, Rabito SF 1998 Ketamine inhibits the tonic response to carbachol and histamine in the guinea pig trachea. Eur J Anaesthesiol 15:486-492

21. Himpens B 1992 Modulation of the $\mathrm{Ca}(2+)$-sensitivity in phasic and tonic smooth muscle. Verh K Acad Geneeskd Belg 54:217-251

22. McHale NG, Thornbury KD, Hollywood MA 2000 5-HT inhibits spontaneous contractility of isolated sheep mesenteric lymphatics via activation of 5-HT(4) receptors. Microvasc Res 60:261-268

23. Potjer RM, Constantinou CE 1989 Frequency of spontaneous contractions in longitudinal and transverse bladder strips. Am J Physiol 257:R781-R787

24. Stork AP, Cocks TM 1994 Pharmacological reactivity of human epicardial coronary arteries: phasic and tonic responses to vasoconstrictor agents differentiated by nifedipine. Br J Pharmacol 113:1093-1098

25. Greenberg SS, Wang Y, Xie J, Smartz L, Rammazatto L, Curro FA 1991 The effect of thromboxane on contraction of canine mesenteric and lingual arteries. J Dent Res 70:1278-1285

26. Roman J 1995 Effects of calcium channel blockade on mammalian lung branching morphogenesis. Exp Lung Res 21:489-502

27. Featherstone NC, Jesudason EC, Connell MG, Fernig DG, Wray S, Losty PD, Burdyga TV 2005 Spontaneous propagating calcium waves underpin airway peristalsis in embryonic rat lung. Am J Respir Cell Mol Biol 33:153-160

28. Ohata H, Kawanishi T, Hisamitsu T, Takahashi M, Momose K 1996 Functional coupling of the $\mathrm{Na}+/ \mathrm{Ca} 2+$ exchanger with $\mathrm{Ca} 2+$ release from intracellular stores in cultured smooth muscle cells of guinea pig ileum. Life Sci 58:1179-1187

29. Janssen LJ 2002 Ionic mechanisms and $\mathrm{Ca}(2+)$ regulation in airway smooth muscle contraction: do the data contradict dogma? Am J Physiol Lung Cell Mol Physiol 282:L1161-L1178

30. Snetkov VA, Pandya H, Hirst SJ, Ward JP 1998 Potassium channels in human fetal airway smooth muscle cells. Pediatr Res 43:548-554

31. Snetkov VA, Hirst SJ, Ward JP 1996 Ion channels in freshly isolated and cultured human bronchial smooth muscle cells. Exp Physiol 81:791-804

32. Somlyo AP, Somlyo AV 2004 Signal transduction through the RhoA/Rho-kinase pathway in smooth muscle. J Muscle Res Cell Motil 25:613-615

33. Wareing M, O'Hara M, Seghier F, Baker PN, Taggart MJ 2005 The involvement of Rho-associated kinases in agonist-dependent contractions of human maternal and placental arteries at term gestation. Am J Obstet Gynecol 193:815-824

34. Ding X, Murray PA 2005 Cellular mechanisms of thromboxane A2-mediated contraction in pulmonary veins. Am J Physiol Lung Cell Mol Physiol 289:L825L833

35. Wilson DP, Susnjar M, Kiss E, Sutherland C, Walsh MP 2005 Thromboxane A2-induced contraction of rat caudal arterial smooth muscle involves activation of $\mathrm{Ca} 2+$ entry and $\mathrm{Ca} 2+$ sensitization: Rho-associated kinase-mediated phosphorylation of MYPT1 at Thr-855, but not Thr-697. Biochem J 389:763-774

36. Harding R, Hooper SB 1996 Regulation of lung expansion and lung growth before birth. J Appl Physiol 81:209-224

37. Wigglesworth JS 1981 Pulmonary hypoplasia with phrenic nerve agenesis. J Pediatr 98:667-668

38. Wigglesworth JS, Desai R 1979 Effect on lung growth of cervical cord section in the rabbit fetus. Early Hum Dev 3:51-65

39. Higuchi M, Hirano H, Gotoh K, Otomo K, Maki M 1991 Relationship between the duration of fetal breathing movements and gestational age and the development of the central nervous system at 25-32 weeks of gestation in normal pregnancy. Gynecol Obstet Invest 31:136-140

40. Kobayashi K, Lemke RP, Greer JJ 2001 Ultrasound measurements of fetal breathing movements in the rat. J Appl Physiol 91:316-320 